\title{
Correction to: Evaluation of hydrochar efficiency for simultaneous removal of diclofenac and ibuprofen from aqueous system using surface response methodology
}

Tahira Qureshi $^{1} \cdot$ Najma Memon $^{1}$ (D) $\cdot$ Saima Q. Memon ${ }^{2} \cdot$ Handan Yavuz $^{3} \cdot$ Abdesadek Lachgar $^{4} \cdot$ Adil Denizli $^{3}$

Published online: 13 March 2019

(C) Springer-Verlag GmbH Germany, part of Springer Nature 2019

Correction to: Environmental Science and Pollution Research https://doi.org/10.1007/s11356-019-04359-z

The original publication of this paper contain typographical mistakes.

The published paper had missed letter ' $\mathrm{H}$ ' in some parts of text, references and figure captions. These changes does not affect the findings of paper.

The original article has been corrected.

Publisher's note Springer Nature remains neutral with regard to jurisdictional claims in published maps and institutional affiliations.

The online version of the original article can be found at https://doi.org/ 10.1007/s11356-019-04359-z

Najma Memon

najmamemon@gmail.com

1 National Centre of Excellence in Analytical Cemistry, University of Sindh, Jamsoro, Sindh, Pakistan

2 Dr.M.A.Kazi Institute of Chemistry, University of Sindh, Jamsoro, Pakistan

3 Biochemistry Department, Hacettepe University, Ankara, Turkey

4 Department of Chemistry, Wake Forest University, Winston-Salem, NC 27109, USA 